\title{
PASS-DIA: A data-independent acquisition approach for discovery studies
}

Dong-Gi Mun ${ }^{1}$, Santosh Renuse ${ }^{1,2}$, Mayank Saraswat ${ }^{1,3,4,5}$, Anil Madugundu ${ }^{1,2,3,4,5}$, Savita Udainiya ${ }^{1,2,3}$, Hokeun Kim ${ }^{6}$, Sung-Kyu Robin Park ${ }^{7}$, Hui Zhao ${ }^{1}$, Raja Sekhar Nirujogi ${ }^{8}$, Chan Hyun $\mathrm{Na}^{9,10}$, Nagarajan Kannan ${ }^{1}$, John R. Yates, III ${ }^{7}$, Sang-Won Lee, ${ }^{6, *}$ and Akhilesh Pandey $1,2,3,4,5,{ }^{*}$

${ }^{1}$ Department of Laboratory Medicine and Pathology, Mayo Clinic, Rochester, MN 55905, USA

${ }^{2}$ Center for Individualized Medicine, Mayo Clinic, Rochester, MN 55905, USA

${ }^{3}$ Center for Molecular Medicine, National Institute of Mental Health and Neurosciences (NIMHANS), Hosur Road, Bangalore 560029, India

${ }^{4}$ Institute of Bioinformatics, International Technology Park, Bangalore 560066, Karnataka, India

${ }^{5}$ Manipal Academy of Higher Education (MAHE), Manipal, 576104 Karnataka, India

${ }^{6}$ Department of Chemistry, Center for Proteogenome Research, Korea University, Seoul 136-701, Republic of Korea

${ }^{7}$ Department of Molecular Medicine and Neurobiology, The Scripps Research Institute, 10550 North Torrey Pines Road, La Jolla, CA 92037, USA

${ }^{8}$ Medical Research Council Protein Phosphorylation and Ubiquitylation Unit, University of Dundee, Dundee DD1 5EH, United Kingdom

${ }^{9}$ McKusick-Nathans Institute of Genetic Medicine, Johns Hopkins University School of Medicine, Baltimore, MD 21205, USA

${ }^{10}$ Neurology, Institute for Cell Engineering, Johns Hopkins University School of Medicine, Baltimore, MD 21205 , USA

*Corresponding authors

Experimental Section. Detailed description of sample preparation

Table S1-5. Summary of experiments performed in this study

Figure S1. Comparison of peptide identifications of PASS-DIA and DDA

Figure S2. The effect of charge state exclusion setting in DDA experiment

Figure S3. The description of UMC-based quantitation

Figure S4. Assessing the performance of PASS-DIA on quantitation

Figure S5. The comparison of UMC-based quantitation and Spectronaut for PASS-DIA data

Figure S6. Annotated MS/MS spectra of synthetic peptides from missing proteins 


\section{EXPERIMENTAL SECTION}

Peptide sample preparation for method development and performance assessment. Lyophilized HeLa protein digest standard (Thermo Scientific, 88328) was used for method development and performance assessment of this study. It was reconstituted in $0.1 \%$ formic acid for LC-MS/MS analysis. Yeast protein extract (Promega, V7341) was digested using trypsin with 1:50 enzyme to sample ratio and E. coli protein digest (Waters, 186003196) were reconstituted in $0.1 \%$ formic acid. Two kinds of peptide mixtures were prepared for performance evaluation of quantitation. Mixture A was consisted of $650 \mathrm{ng}$ of $\mathrm{HeLa}, 150 \mathrm{ng}$ of yeast and $200 \mathrm{ng}$ of $E$. coli peptides. Mixture B was prepared with $650 \mathrm{ng}$ of HeLa, 300 ng of yeast and $200 \mathrm{ng}$ of $E$. coli peptides (Supplementary Figure S2B). The samples for the conventional DIA experiments, 200 fmol equivalent iRT peptides (Biognosys, Ki-3002-1) were spiked to be processed with Spectronaut.

Strong cation exchange chromatography. HEK-293T cells were prepared in-house and dissolved in $8 \mathrm{M}$ urea in 50mM triethylammonium bicarbonate (TEAB) buffer $(\mathrm{pH} 8.0)$. Cells were lysed using tip sonicator (Branson, SFX 550) for 30 seconds. Protein lysates were reduced using $10 \mathrm{mM}$ dithiothreitol (Sigma, D9163) for 1 hour at $37^{\circ} \mathrm{C}$ followed by alkylation using $40 \mathrm{mM}$ iodoacetamide (Sigma, I1149) for $30 \mathrm{~min}$ at room temperature. Trypsin digestion was performed with 1:50 enzyme to sample ratio for overnight at $37^{\circ} \mathrm{C}$.SCX chromatography was performed using Dionex Ultimate 3000 system (Thermo Fisher Scientific). Buffer A (25 mM ammonium formate in $20 \%$ acetonitrile, pH 2.7) and buffer B (300 $\mathrm{mM}$ ammonium formate in $20 \%$ acetonitrile, $\mathrm{pH} 3.0$ ) were prepared. Tryptic peptides of HEK-293T cells ( $\sim 4 \mathrm{mg}$ ) were cleaned up using $\mathrm{C}_{18}$ tips (Glygen, TT2C18) and resuspended in buffer A. The samples were injected to PolySULFOETHYL A SCX column (PolyLC, $4.6 \mathrm{~mm}$ ID $200 \mathrm{~mm}$ length) and separated over 60 min following the gradient: buffer A 100\% during initial $10 \mathrm{~min}$, from 0 to $5 \%$ buffer B in 2 min, from 5\% to $50 \%$ buffer B till 50 min, increasing to $100 \%$ buffer B in 2 min, keeping $100 \%$ buffer B for 4 min and $100 \%$ buffer A for 4 min. Eluted peptides were collected every 75 sec generating total 48 fractions. Fractions eluting before actual gradient starting (four fractions) containing enriched phosphorylated and N-terminal acetylated peptides were dried and reconstituted in $0.1 \%$ formic acid for LC-MS/MS analysis.

Preparation of fallopian tube organoids. Human fallopian tube organoids were obtained from Mayo Clinic Fallopian Tube Organoid Biobank (IRB No.18-001967). Study samples were approved by Mayo Clinic's Institutional Review Board (IRB-18-007521). Organoids were generated as previously described ${ }^{1}$. Briefly, the fallopian cells were cultured in 2-dimensional culture system for 8 days and transferred to 3-dimentional matrigel culture system and maintained in an organoid expansion media for up to 11 days at $5 \% \mathrm{CO}_{2}$ and $5 \% \mathrm{O}_{2}$. Hundred organoids were washed in cold PBS, transferred to a microfuge tube and centrifuged at $300 \mathrm{~g}$ for $5 \mathrm{~min}$. Acquired organoids were lysed in $8 \mathrm{M}$ urea buffer (50mM triethylammonium bicarbonate, $\mathrm{pH} 8.5$ ). Reduction, alkylation and digestion were performed following the same procedure of the HEK-293T cells.

Glycopeptide enrichment. Cell surface N-glycopeptides were enriched using multi-lectin affinity chromatography at the peptide level. Briefly, MCF10A cells were cultured and lysed in modified RIPA buffer with added protease inhibitors. Cells were lysed with tip sonicator for three pulses of 5 seconds each and kept on ice in between the pulses. Sonicated lysate was cleared by centrifuging at 16,000g for 10 minutes and supernatant was collected. Cleared lysate was used for precipitating $6 \mathrm{mg}$ of total protein by chilled acetone. Pellet was dissolved in $8 \mathrm{M}$ urea, $50 \mathrm{mM}$ TEAB buffer $\mathrm{pH} 8.0$ and proteins were reduced by $10 \mathrm{mM}$ DTT for 45 minutes at $65^{\circ} \mathrm{C}$ followed by alkylation at $40 \mathrm{mM}$ iodoacetamide for 15 minutes at room temperature. After diluting to reduce urea concentration below $1 \mathrm{M}$, trypsin was added at 1:50 for total amount of proteins followed by incubation at $37^{\circ} \mathrm{C}$ for 18 hours. Trypsin was inactivated by acidification and peptides were adjusted to binding buffer consisted of 10mM HEPES buffer ( $\mathrm{pH} 7.4)$ with $0.1 \mathrm{mM} \mathrm{CaCl}_{2}, 1 \mathrm{mM} \mathrm{MgCl}$ and $1 \mathrm{mM} \mathrm{MnCl}_{2}$. Peptides in HEPES buffer were added to the multilectin mix resin slurry $\left(2 \mathrm{~mL}\right.$ of ConA: SNA: LCA: AAL at 4:2:2:1 $(100 \mu \mathrm{l}$ each) $)$ and incubated at $4^{\circ} \mathrm{C}$ overnight with shaking. ConA (AL1003), LCA (AL1043), AAL (AL1393), and SNA (AL1303) were 
purchased from Vector Laboratories. After washing the resin with $2 \mathrm{~mL}$ binding buffer three times, bounded glycopeptides were eluted with $2 \%$ formic acid and cleaned with $\mathrm{C}_{18}$ tips.

\section{References}

(1) Kessler, M.; Hoffmann, K.; Brinkmann, V.; Thieck, O.; Jackisch, S.; Toelle, B.; Berger, H.;

Mollenkopf, H. J.; Mangler, M.; Sehouli, J.; Fotopoulou, C.; Meyer, T. F. Nat Commun 2015, 6, 8989. 
Supplementary Table 1-5. Summary of experiments performed in this study. The parameters for data acquisition and data analysis strategy are shown for each of samples analyzed.

\section{Supplementary Table 1}

Sample: HeLa

\begin{tabular}{|c|c|c|c|c|}
\hline & $\begin{array}{c}\text { Conventional } \\
\text { DDA }\end{array}$ & DDA & PASS-DIA & $\begin{array}{c}\text { Conventional } \\
\text { DIA }\end{array}$ \\
\hline Number of LC-MS/MS run & 7 & 7 & 7 & 7 \\
\hline $\begin{array}{c}\text { m/z range of MS scan } \\
\text { (Mass range per run) }\end{array}$ & $\begin{array}{c}350-1400 \mathrm{~m} / \mathrm{z} \\
(1,050 \mathrm{~m} / \mathrm{z})\end{array}$ & $\begin{array}{c}350-1400 \mathrm{~m} / \mathrm{z} \\
(150 \mathrm{~m} / \mathrm{z})\end{array}$ & $\begin{array}{c}350-1400 \mathrm{~m} / \mathrm{z} \\
(150 \mathrm{~m} / \mathrm{z})\end{array}$ & $\begin{array}{c}350-1400 \mathrm{~m} / \mathrm{z} \\
(1,050 \mathrm{~m} / \mathrm{z})\end{array}$ \\
\hline Isolation window & $2 \mathrm{~m} / \mathrm{z}$ & $2 \mathrm{~m} / \mathrm{z}$ & $2 \mathrm{~m} / \mathrm{z}$ & $15 \mathrm{~m} / \mathrm{z}$ \\
\hline Precursor mass assignment & & & $\begin{array}{c}\mathrm{mPE}-\mathrm{MMR} \\
\text { RawConverter }\end{array}$ & \\
\hline Peptide identification & SEQUEST & $\begin{array}{c}\text { SEQUEST } \\
\text { MS-GF+ }\end{array}$ & $\begin{array}{c}\text { SEQUEST } \\
\text { MS-GF+ }\end{array}$ & Spectronaut \\
\hline
\end{tabular}

\section{Supplementary Table 2}

Sample: Mixture of HeLa, yeast and E. coli

\begin{tabular}{|c|c|c|c|}
\hline & DDA & PASS-DIA & $\begin{array}{c}\text { Conventional } \\
\text { DIA }\end{array}$ \\
\hline Number of LC-MS/MS run & 3 & 3 & 3 \\
\hline $\begin{array}{c}\text { m/z range of MS scan } \\
\text { (Mass range per acquisition) }\end{array}$ & $\begin{array}{c}500-650 \mathrm{~m} / \mathrm{z} \\
(150 \mathrm{~m} / \mathrm{z})\end{array}$ & $\begin{array}{c}500-650 \mathrm{~m} / \mathrm{z} \\
(150 \mathrm{~m} / \mathrm{z})\end{array}$ & $\begin{array}{c}350-1400 \mathrm{~m} / \mathrm{z} \\
(1,050 \mathrm{~m} / \mathrm{z})\end{array}$ \\
\hline Isolation window & $2 \mathrm{~m} / \mathrm{z}$ & $2 \mathrm{~m} / \mathrm{z}$ & $15 \mathrm{~m} / \mathrm{z}$ \\
\hline Precursor mass assignment & & $m$ PE-MMR & \\
\hline Peptide identification & SEQUEST & SEQUEST & Spectronaut \\
\hline
\end{tabular}

\section{Supplementary Table 3}

Sample: HEK-293 cells

Enrichment: SCX chromatography

\begin{tabular}{|c|c|c|}
\hline & DDA & PASS-DIA \\
\hline Number of LC-MS/MS run & 6 & 6 \\
\hline $\begin{array}{c}\text { m/z range of MS scan } \\
\text { (Mass range per acquisition) }\end{array}$ & $\begin{array}{c}500-1400 \mathrm{~m} / \mathrm{z} \\
(150 \mathrm{~m} / \mathrm{z})\end{array}$ & $\begin{array}{c}500-1400 \mathrm{~m} / \mathrm{z} \\
(150 \mathrm{~m} / \mathrm{z})\end{array}$ \\
\hline Isolation window & $2 \mathrm{~m} / \mathrm{z}$ & $2 \mathrm{~m} / \mathrm{z}$ \\
\hline Precursor mass assignment & & $m$ PE-MMR \\
\hline Peptide identification & SEQUEST & SEQUEST \\
\hline
\end{tabular}




\section{Supplementary Table 4}

Sample: MCF10A cells

Enrichment: Multi-lectin affinity chromatography

\begin{tabular}{|c|c|c|}
\hline & DDA & PASS-DIA \\
\hline Number of LC-MS/MS run & 10 & 10 \\
\hline $\begin{array}{c}\text { m/z range of MS scan } \\
\text { (Mass range per acquisition) }\end{array}$ & $\begin{array}{c}500-2000 \mathrm{~m} / \mathrm{z} \\
(150 \mathrm{~m} / \mathrm{z})\end{array}$ & $\begin{array}{c}500-2000 \mathrm{~m} / \mathrm{z} \\
(150 \mathrm{~m} / \mathrm{z})\end{array}$ \\
\hline Isolation window & $2 \mathrm{~m} / \mathrm{z}$ & $2 \mathrm{~m} / \mathrm{z}$ \\
\hline Precursor mass assignment & & $\mathrm{mPE}-\mathrm{MMR}$ \\
\hline Peptide identification & pGlyco 2.2 & pGlyco 2.2 \\
\hline
\end{tabular}

\section{Supplementary Table 5}

Sample: Fallopian tube organoids

\begin{tabular}{|c|c|c|}
\hline & DDA & PASS-DIA \\
\hline Number of LC-MS/MS run & 7 & 7 \\
\hline $\begin{array}{c}\text { m/z range of MS scan } \\
\text { (Mass range per acquisition) }\end{array}$ & $\begin{array}{c}350-1400 \mathrm{~m} / \mathrm{z} \\
(150 \mathrm{~m} / \mathrm{z})\end{array}$ & $\begin{array}{c}350-1400 \mathrm{~m} / \mathrm{z} \\
(150 \mathrm{~m} / \mathrm{z})\end{array}$ \\
\hline Isolation window & $2 \mathrm{~m} / \mathrm{z}$ & $2 \mathrm{~m} / \mathrm{z}$ \\
\hline Precursor mass assignment & & $m$ PE-MMR \\
\hline Peptide identification & SEQUEST & SEQUEST \\
\hline
\end{tabular}




\section{A}
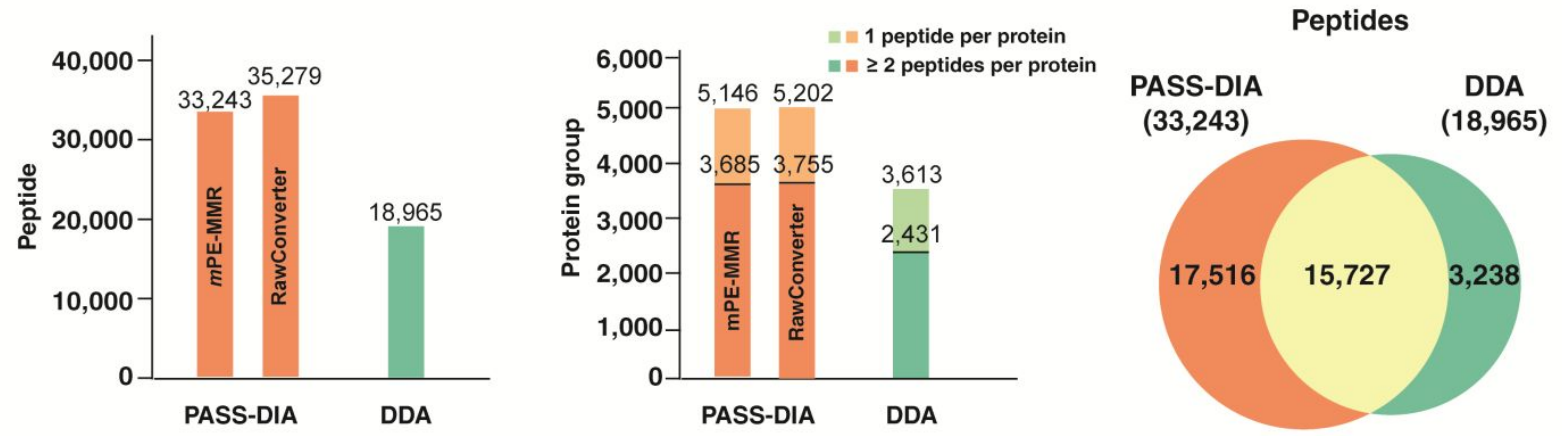

B
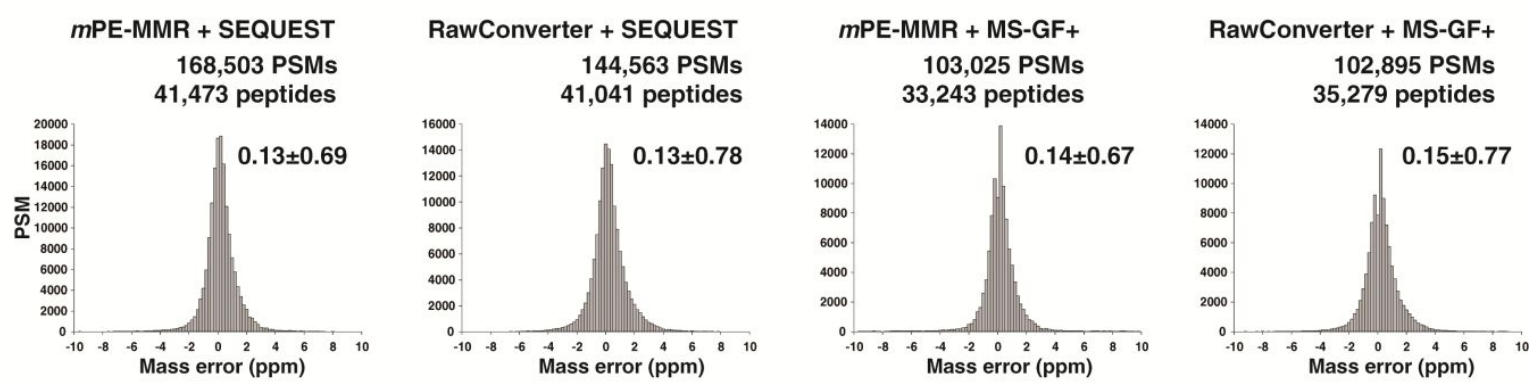

C

Peptides

PASS-DIA
$(41,473)$

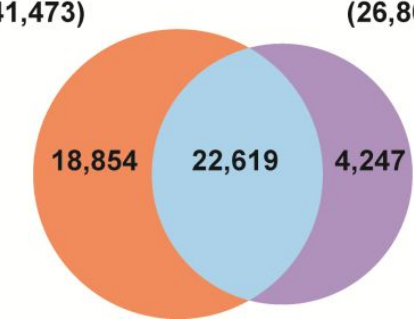

Protein groups ( $\geq 2$ peptides)

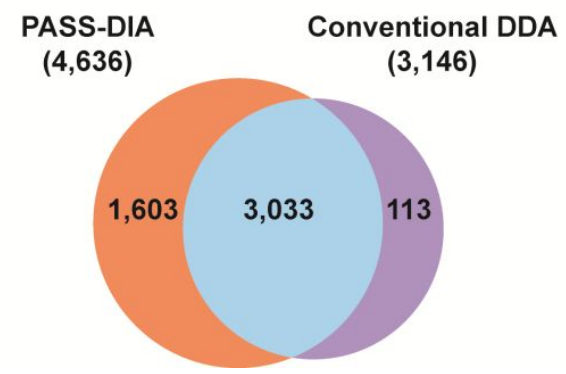

Figure S1. (A) Summary of identified peptides and protein groups through DDA and PASS-DIA when MS-GF+ was applied for protein database search engine. (B) The number of PSMs and identified peptides are shown with their mass measurement error distribution. (C) Venn diagrams showing comparison between PASS-DIA and DDA on peptides and protein groups ( $\geq 2$ peptides). 
A

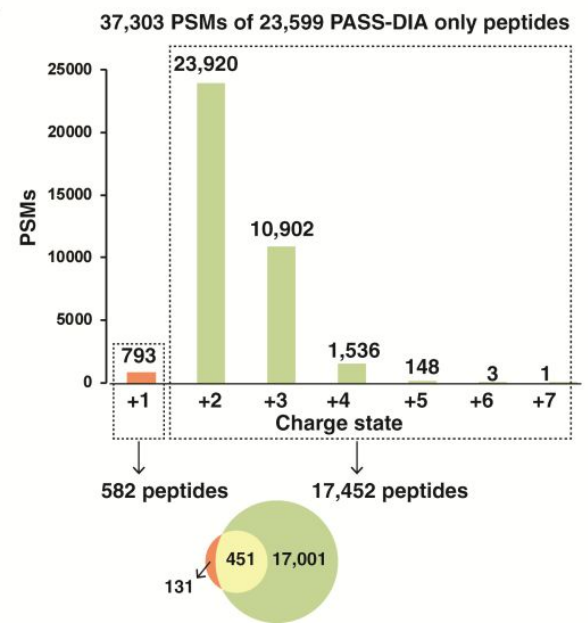

B

Effect of charge state exclusion settting on peptide identification in DDA experiment

\begin{tabular}{lcc:c:}
\hline & $\begin{array}{l}\text { Unassigned, } \\
+1, \geq+6\end{array}$ & $\begin{array}{l}\text { Unassigned, } \\
\geq+6\end{array}$ & $>+7$ \\
\hline Peptide & 8,252 & 8,658 & 10,281 \\
\hline SEQUEST & & & $\downarrow$ \\
& & & \\
PASS-DIA [500-650 m/z] & & DDA $[500-650 \mathrm{~m} / \mathrm{z}]$
\end{tabular}

$(18,456)$

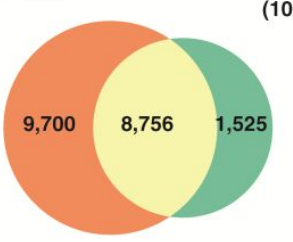

Figure S2. (A) The charge state distribution of PASS-DIA only peptides. (B) Table summarizes the number of identified peptides in the various mass spectrometry settings of charge state exclusion. Venn diagram showing comparison of peptides between PASS-DIA and DDA acquired from 500-650 m/z. Precursor ions with charge state of $+1,+6$ and unassigned were included for MS/MS scan event during DDA experiment. 


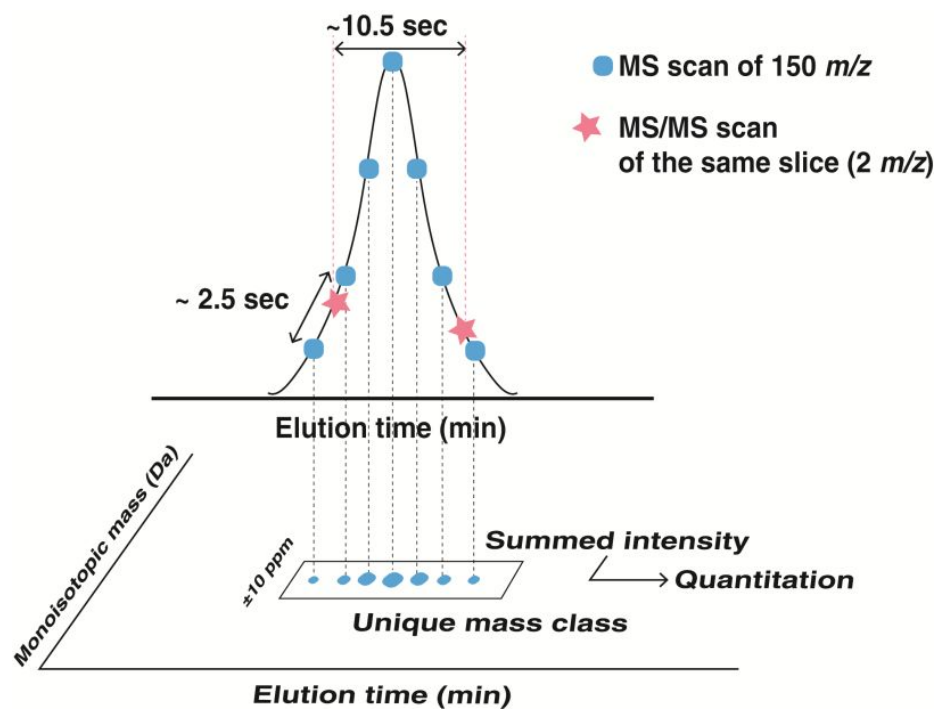

Figure S3. Illustration describing the time between MS scan and MS/MS scan of PASS-DIA experiment. Unique mass classes (UMCs) were generated during $m$ PE-MMR process and their summed intensities were used for MS based quantitation. 
A

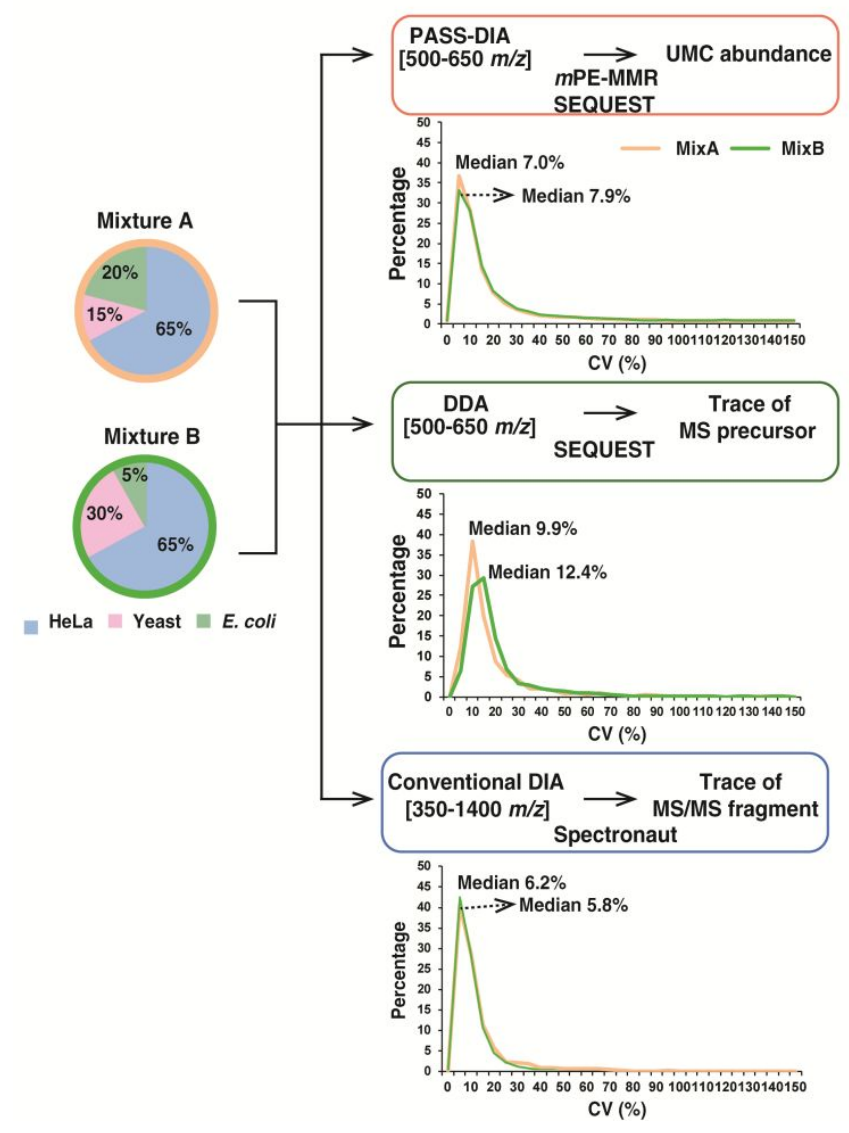

B

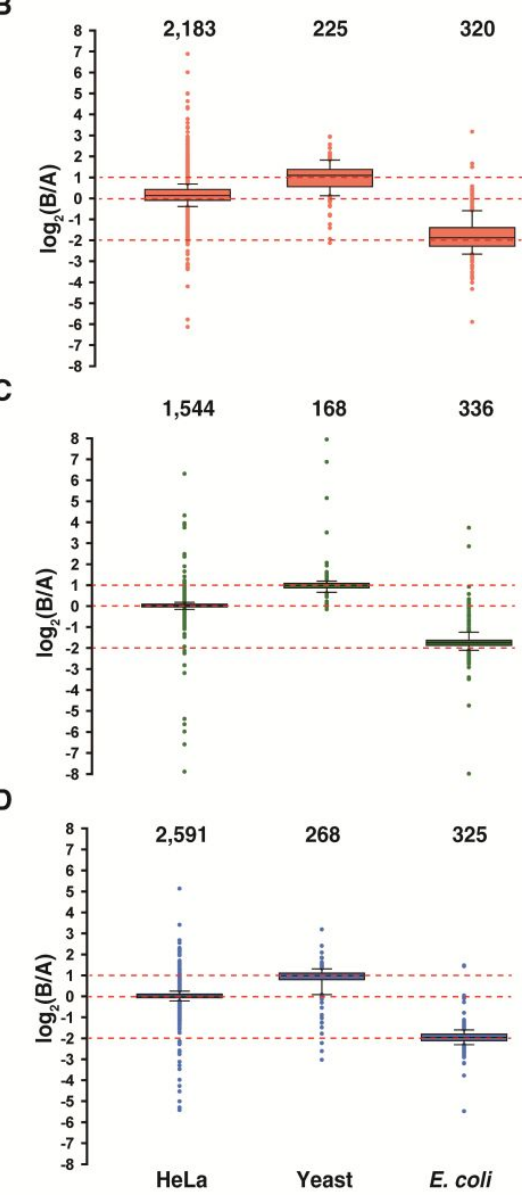

Figure S4. (A) The workflow for generating HeLa, yeast and E. coli mixtures for evaluating performance of PASSDIA on quantitation. Triplicates of PASS-DIA, DDA, and conventional DIA experiments were performed on each of the mixtures followed by identification and quantitation. The distributions of coefficient of variation (CV) of quantified protein are shown for each of approaches along with median CV values. Fold-changes are plotted as boxplot of $\log _{2}(\mathrm{~B} / \mathrm{A})$ value for (B) PASS-DIA, (C) DDA, and (D) conventional DIA experiment. The boundary of the boxes indicate 25 th and $75^{\text {th }}$ percentile while the line within the box represents the median value. The whiskers indicate the 10th 90th percentiles. Outliers are represented as dots. The expected value of $\log _{2}(\mathrm{~B} / \mathrm{A})$ are 0,1 and -2 , respectively and marked as red dotted line. The number of quantified proteins is denoted in each of plots. 


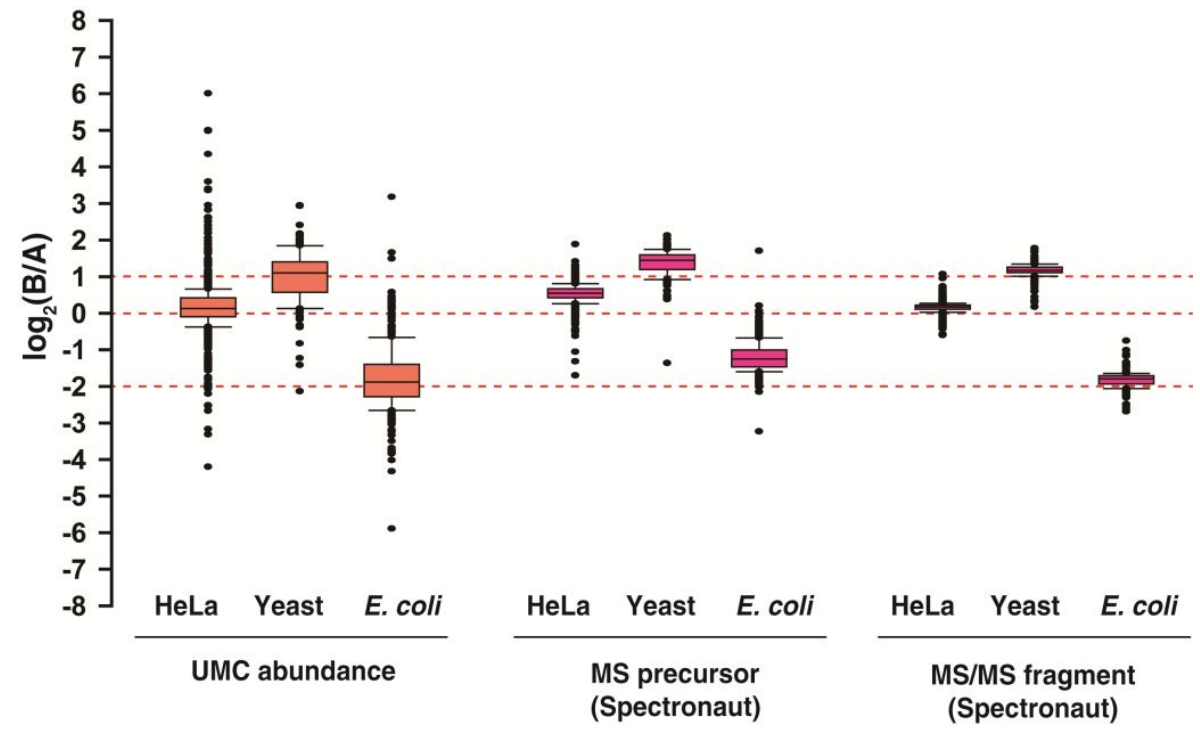

Figure S5. A boxplot of fold-changes for proteins quantified by both UMC-based quantitation and Spectronaut from PASS-DIA data. 
NX_Q5SRD1-1, TIMM23B

Putative mitochondrial import inner membrane translocase subunit Tim23B NVQILNMVTR

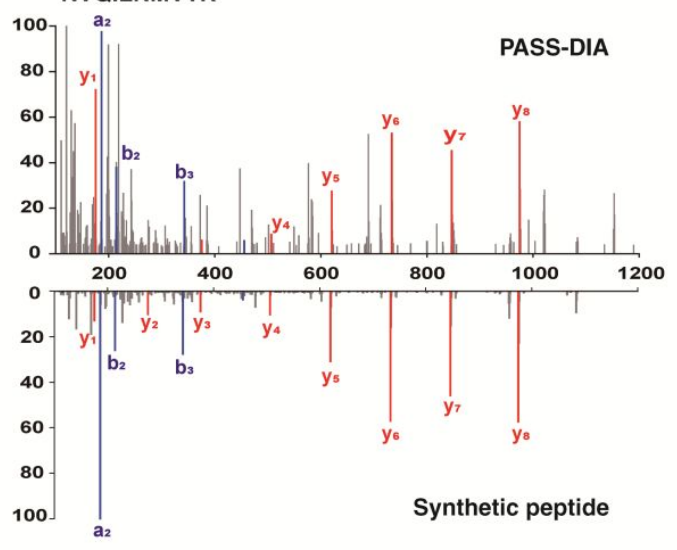

NX_060361-1, NME2P1

Putative nucleoside diphosphate kinase FKPEELVDYK

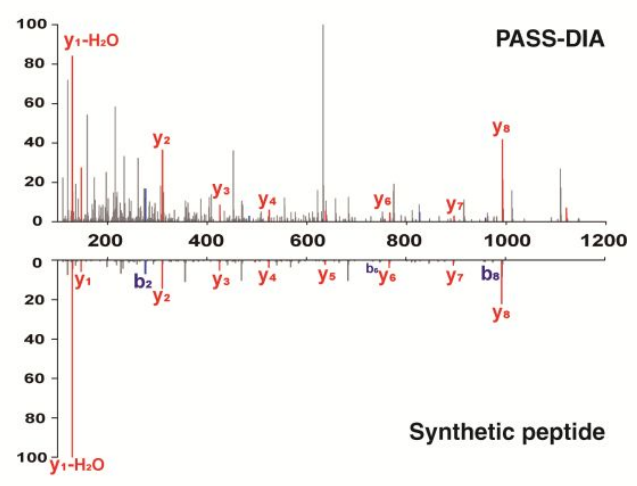

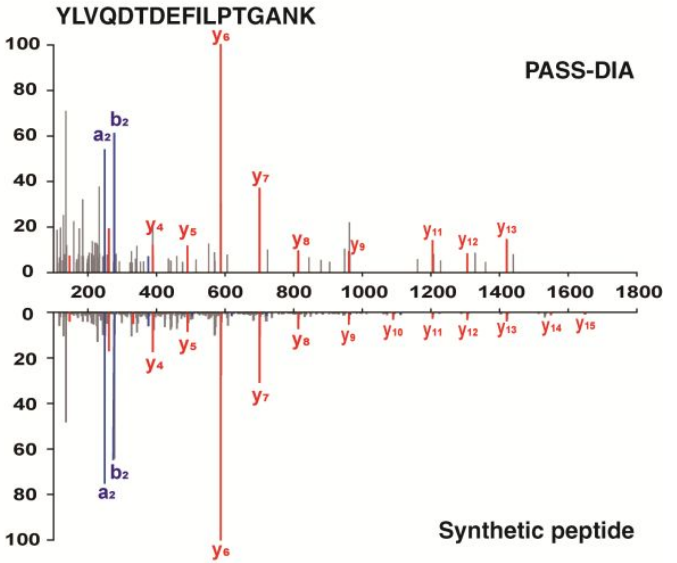

Figure S6. (A) The annotated MS/MS spectra of three peptides corresponding to two missing proteins (TIMM23B and NME2P1) are described along with MS/MS spectra acquired using synthetic peptides. 